IGG4-АССОЦИИРОВАННЫЕ ЗАБОЛЕВАНИЯ В ЭНДОКРИНОЛОГИИ

( П.О. Румянцев ${ }^{1 *}$, И.Г. Козлов ${ }^{2,3}$, Е.А. Колпакова' ${ }^{1}$ О.С. Чухачева, С.В. Коренев ${ }^{3}$, А.Г. Гончаров ${ }^{3}$, Е.Ю. Уланова ${ }^{4}$

'Национальный медицинский исследовательский центр эндокринологии, Москва, Россия

${ }^{2}$ Национальный медицинский исследовательский центр детской гематологии, онкологии и иммунологии им. Дмитрия Рогачева, Москва, Россия

${ }^{3}$ Балтийский федеральный университет имени Иммануила Канта, Калининград, Россия

${ }^{4}$ Первый Московский государственный медицинский университет имени И.М. Сеченова (Сеченовский университет), Москва, Россия

Иммуноглобулин-G4-ассоциированные заболевания (IgG4-A3) - это хроническая иммуноопосредованная патология различных органов локального или системного характера, которая была выделена в самостоятельную нозологическую единицу только в начале XXI в. и характеризуется муароподобным фиброзным воспалением пораженных тканей, их увеличением, а также повышением уровня сывороточного иммуноглобулина G4 (IgG4). Наиболее распространенными проявлениями заболевания являются отек слюнных и слезных желез, лимфаденопатия и аутоиммунный панкреатит 1-го типа (АИП1), однако могут быть вовлечены другие органы (щитовидная железа, глаза, мозговые оболочки, сердце, легкие, почки, аорта, верхние дыхательные пути, брыжейка и др.).

Эффективность лечения IgG4-A3, как и других патологических состояний, определяется в том числе своевременностью диагностики. Однако последний пункт затруднен в силу разнообразия клинических проявлений и довольно изменчивых диагностических критериев. Для преодоления этого барьера необходима постоянная актуализация доказательных знаний и диагностических алгоритмов в рамках данной патологии с привлечением иммунологов, эндокринологов, патологов и специалистов других областей.

В данном обзоре представлены сведения об этиологии, патогенезе, современных методах диагностики и лечения lgG4-ассоциированных заболеваний, а также приведены примеры некоторых проявлений IgG4-A3, с которыми может на практике столкнуться врач-эндокринолог.

КЛЮЧЕВЫЕ СЛОВА: иммуноглобулин-G4-ассочиированные заболевания, болезнь Микулича, опухоль Кюттнера, тиреоидит Риделя, иммуноглобулин-G4-ассоциированная офтальмопатия, иммуногенез.

\title{
IGG4-RELATED DISEASES IN ENDOCRINOLOGY
}

(c) Pavel O. Rumyantsev*, Ivan G. Kozlov2,3, Evgeniya A. Kolpakova1, Olga S. Chukhacheva, Sergey V. Korenev³, Andrey G. Goncharov³ ${ }^{3}$ Elena U. Ulanova ${ }^{4}$

'Endocrinology Research Centre, Moscow, Russia

${ }^{2}$ D. Rogachev Federal Research and Clinical Center for Pediatric Hematology, Oncology and Immunology, Moscow, Russia

${ }^{3}$ Immanuel Kant Baltic Federal University, Kaliningrad, Russia

${ }^{4}$ Federal State Autonomous Educational Institution of Higher Education I.M. Sechenov First Moscow State Medical

University (Sechenovskiy University), Moscow, Russia

Immunoglobulin-G4-related disease (IgG4-RD) is a chronic immunomediated pathology of different organs of local or systemic nature, which has been established as a separate clinical entity in the early 2000 s and is characterized by storiform fibroid inflammation of the affected tissues, their increase, and elevated serum immunoglobulin-G4 (lgG4) levels. The most common manifestations of the disease are major salivary and lacrimal gland enlargement, lymphadenopathy and type 1 autoimmune pancreatitis (AIP1), however, other organs may be also involved (the thyroid, eyes, meninges, heart, lungs, kidneys, aorta, upper airways, mesentery, etc.).

The effectiveness of treatment of lgG4-RD, as well as other pathological conditions, is also determined by the timely diagnosis. However, the latter is complicated due to the variety of clinical manifestations and rather variable diagnostic criteria. It is necessary to constantly update the evidence-based knowledge and diagnostic algorithms within this pathology in order to overcome the difficulties, and involve immunologists, endocrinologists, pathologists and specialists in other spheres.

This review provides information about the etiology, pathogenesis, and current methods of diagnosis and treatment of IgG4-related diseases, as well as examples of some manifestations of lgG4-RD that an endocrinologist may face in practice.

KEYWORDS: Immunoglobulin-G4-related diseases, Mikulicz disease, Kuttner tumor, Riedel's thyroiditis, IgG4-related ophthalmic disease, immunogenesis. 


\section{КЛАССИФИКАЦИЯ И ФУНКЦИИ РАЗЛИЧНЫХ КЛАССОВ ИММУНОГЛОБУЛИНОВ}

Иммуноглобулины являются одними из важнейших факторов гуморального иммунитета и обеспечивают защиту от всех видов патогенов и большинства опухолевых клеток. У человека иммуноглобулины представлены 5 классами (G, M, A, E и D). При первичном контакте иммунокомпетентных клеток с чужеродными антигенами происходит инициация синтеза специфических иммуноглобулинов класса M (lgM), затем под влиянием Т-клеток и цитокинов В-клетки переключаются на синтез иммуноглобулинов класса $\mathrm{G}(\mathrm{lgG})$ и других классов. IgG составляют 75\% общего количества антител и подразделяются на 4 подкласса (lgG1-lgG4) в зависимости от наличия одного из четырех типов тяжелых цепей ( $11-\gamma 4)$ и уровня содержания в сыворотке. Количественно больше всего антител относится к подклассу $\lg \mathrm{G} 1$, наименьшее количество - lgG4, составляющие всего 4\% относительной концентрации иммуноглобулинов сыворотки крови [1].

В нормальных условиях гуморальный иммунный ответ на большинство антигенов приводит к синтезу антител всех четырех подклассов lgG. Это осложняет понимание роли каждого из подклассов в элиминации антигена из организма. По одной из наиболее вероятных концепций предполагается, что антительный ответ растянут по времени с постепенным подключением все новых классов и субклассов иммуноглобулинов по мере невозможности эффективной элиминации антигена предыдущими. По этой концепции первичный (острый) ответ на антиген начинается c lgM (многократно подтверждено в эксперименте и клинической практике), затем к нему подключаются IgG3 (и/или lgE). Если элиминации антигена не происходит, активируется синтез IgG1 и IgG2. И, наконец, если и этого недостаточно, начинается продукция IgG4. Считается, что параллельно с переключением субклассов lgG происходит увеличение аффинности антител, за счет чего антитела следующего субкласса обладают преимуществом в связывании антигена, невзирая на их общее количество.

Таким образом, IgG4 является маркером хронизации иммунного ответа или показателем многократности иммунного ответа на один и тот же антиген. Например, возрастание титров IgG4-антител обнаруживается при хронических паразитарных инфекциях, при проведении длительной аллергенспецифической терапии пациентам с атопией [2] или при хронических вирусных инфекциях [3].

Точная функция IgG4-антител неизвестна. Из доказанных фактов: IgG4-антитела вырабатываются в основном в ответ на полисахаридные или карбогидратные антигены; часто являются бивалентными и не способны активировать комплемент (что суммарно затрудняет элиминацию антигена из организма с их помощью); проникают через плацентарный барьер (так же, как IgG1 и IgG3); имеют умеренную аффинность к Fс-рецепторам на фагоцитах, причем в основном к субтипу этих рецепторов, обеспечивающему противовоспалительную активность, - очевидно, с клинической точки зрения это должно проявляться в виде снижения симптоматики заболеваний на фоне продолжения патологическо- го процесса. Данный феномен обусловлен выработкой противовоспалительных цитокинов при соединении IgG4 c Fc-рецепторами на фагоцитах, что будет более подробно описано ниже [4].

\section{IGG4-A3}

Многие заболевания человека сопровождаются изменениями сывороточного и тканевого содержания антител. Долгое время аутоиммунные патологические состояния со схожей гистологической картиной, такие как аутоиммунный панкреатит, опухоль Кюттнера, тиреоидит Риделя, склерозирующий холангит, ретроперитонеальный фиброз (в т.ч. мультифокальный фибросклероз) и другие (офтальмопатия, псевдоопухоль орбиты, менингит, мастоидит, отит, ларингит, фарингит, ринит, риносинусит, лимфаденит, панкреатит, холангит, пневмония, перикардит, мастит, тубулоинтерстициальный нефрит, простатит, аневризмы и прочее) считались самостоятельными заболеваниями (рис. 1).

Только в последние десятилетия исследователи из центров со всего мира заговорили о схожем патологическом механизме развития данных состояний и возможном синдромальном проявлении одного и того же заболевания, что может принципиально изменить подходы к их диагностике и лечению. Некоторые заболевания, которые прежде связывали с вовлечением одного органа, в настоящее время рассматривают как проявления IgG4-ассоциированных заболеваний (IgG4-A3) [5].

lgG4-A3 были выделены в отдельную группу аутоиммунной патологии лишь в начале XXI в., когда в 2001 г. Hamano и соавт. выявили связь всех перечисленных выше заболеваний с повышенным уровнем продукции IgG4. IgG4-АЗ - это хроническая иммуноопосредованная патология различных органов, характеризующаяся муароподобным фиброзным воспалением пораженных тканей, их увеличением (отеком) и обильной инфильтрацией IgG4-положительными плазматическими клетками, а также повышением уровня сывороточного IgG4 [6].

lgG4-A3 часто диагностируют на этапе заметных изменений в органе, нарушения его функции или случайно при проведении биопсии в попытке верифицировать иную патологию. При отсутствии лечения заболевание приводит к фиброзу и необратимому повреждению органов [7]. Наиболее часто lgG4-А3 манифестирует в виде поражения слюнных и слезных желез, лимфаденопатии и аутоиммунного панкреатита 1 типа [8].

\section{этиология IGG4-A3}

Как и для остальных аутоиммунных заболеваний, этиология IgG4-A3 остается до конца не изученной. Традиционно предполагаются наличие генетической предрасположенности и влияние целого ряда эпигенетических факторов в инициации и дальнейшем развитии заболевания.

Сегодня на основе генетических исследований установлены некоторые изменения в геноме, которые могут создать статистическую вероятность предрасположенности к IgG4-A3 [9]. Это, прежде всего, определенные вариации генов, относящихся к главному комплексу 


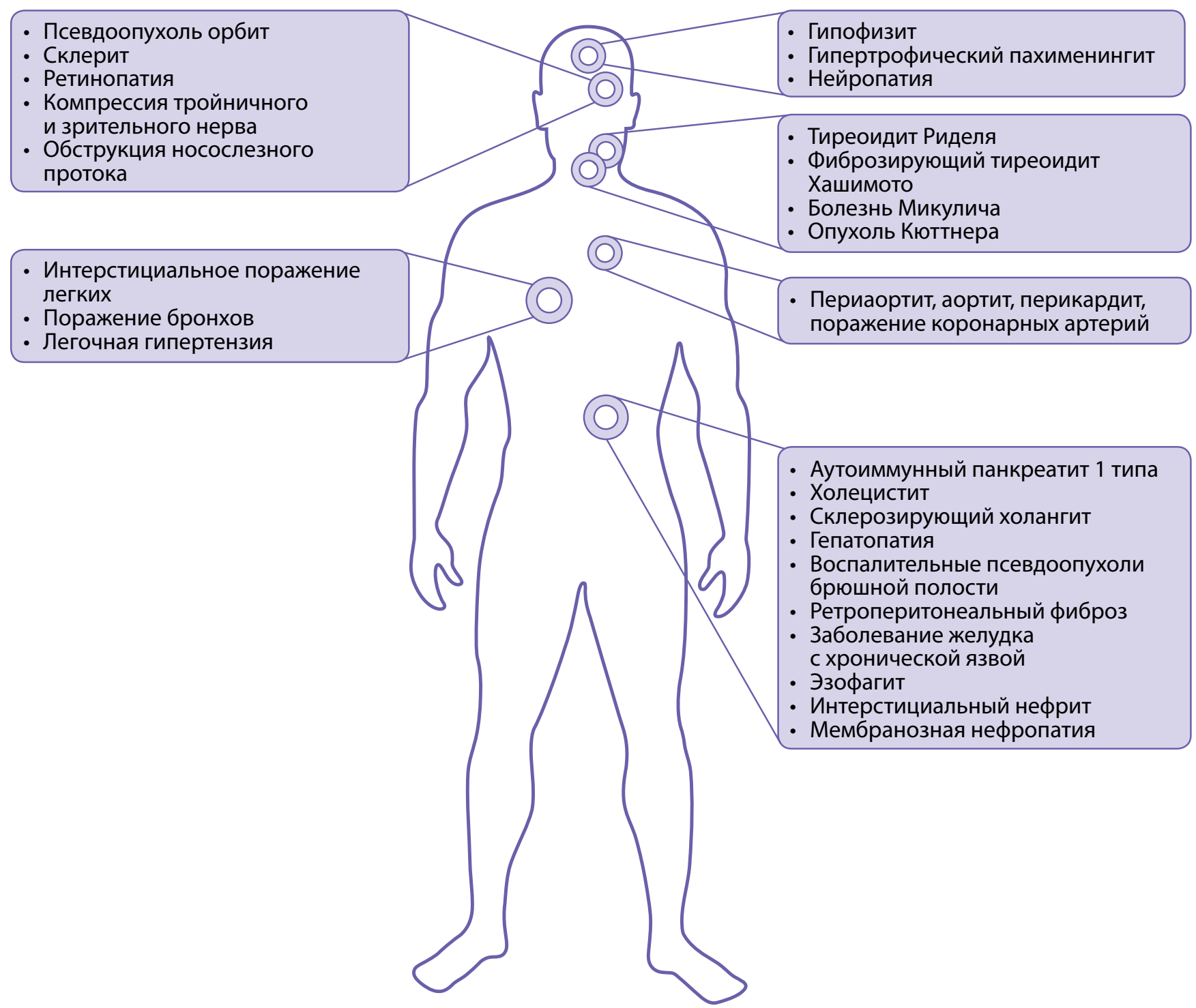

Рисунок 1. Варианты клинической манифестации IgG4-ассоциированных заболеваний.

гистосовместимости (HLA-DR), и мононуклеотидные полиморфизмы значимых генов (SNP). Однако для верификации генетических компонентов заболевания требуются дальнейшие исследования [9].

В связи с низкой практической значимостью определения генетической предрасположенности к неизлечимым заболеваниям в условиях отсутствия рутинных технологий редактирования генома гораздо больший интерес вызывает установление эпигенетических изменений, приводящих к возникновению и прогрессии болезни, в частности, оценка пусковых механизмов патогенеза lgG4-A3 (см. следующий раздел).

\section{ИММУНОПАТОГЕНЕЗ IGG4-A3}

Точный иммунопатогенез lgG4-А3 в настоящее время неизвестен, что может быть обусловлено недостаточными знаниями о функции IgG4 в норме. Однозначно при данных заболеваниях имеются нарушения Т-хелперного (Th) баланса и, в частности, изменения в регулирующих гуморальный ответ Th2. Но остается вопрос: является ли lgG4 «свидетелем» (маркером) или патогенетическим фактором IgG4-A3.
Несмотря на это, исходя из свойств IgG4 и его роли в иммунном ответе на различные антигены, можно сформировать достаточно достоверную гипотезу развития lgG4-A3. Как уже упоминалось, целый ряд характеристик IgG4 делает антитела этого субкласса «особенными» с точки зрения реализации гуморального иммунного ответа. Высокая по сравнению с другими субклассами IgG аффинность к антигену делает IgG4 приоритетным в борьбе за связывание антигена, но дивалентность (практический аналог моновалентности) не позволяет сформировать полноценные иммунные комплексы для элиминации антигена, что способствует его персистенции. Низкая способность связывать и активировать компоненты комплемента - еще один механизм «затягивания» и хронизации иммунного ответа без финальной элиминации причины, его вызывающей, т.е. антигена. И наконец, преимущественное взаимодействие IgG4 с ингибирующими Fc-рецепторами фагоцитов (FcyRIIB), через которые запускается продукция противовоспалительных цитокинов, создает уникальную ситуацию, когда идет патологический процесс без яркой симптоматики, которая обычно заставляет пациента обращаться к врачу. Это приводит, с одной стороны, к поздней 


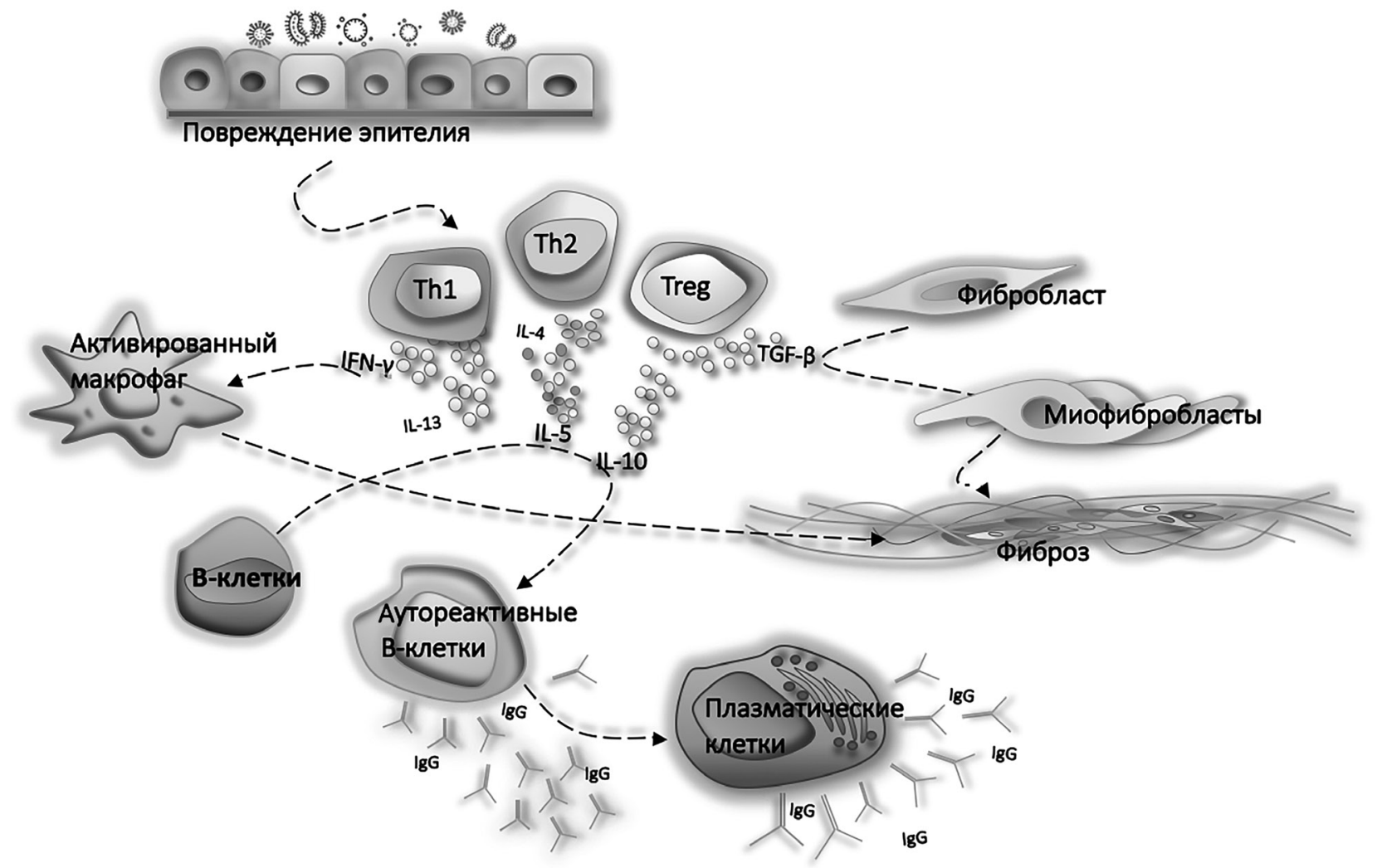

Рисунок 2. Схема иммунопатогенеза IgG4-ассоциированных заболеваний.

Аномальный иммунный ответ на повреждение тканей, аллергены, комменсальные или патогенные микроорганизмы с дисбалансом Тh2-ответа, очевидно, является триггером развития IgG4-A3. Одновременно активированные Th1, Th2 и Treg продуцируют IFN- $\gamma$, IL-4, IL-5, IL-13, IL-10, IL-21 и TGF- $\beta$. Treg продуцируют TGF $\beta-1$, который активирует фибробласты и индуцирует дифференцировку эндотелиальных и эпителиальных клеток в миофибробласты, в результате чего развивается фиброз тканей [8]. IL-4 и IL-10 управляют активацией аутореактивных B-клеток с образованием IgG4 и IgE, а также индуцируют дифференцировку и репликацию плазматических клеток в IgG4+. IL-5, IL-13 и TGF- $\beta$ активируют фибробласты и эозинофилы. IFN- $\gamma$ также может способствовать активации макрофагов и фиброзированию поврежденных тканей; IgG4- и IgE-антитела могут перекрестно реагировать с аутоантигеном. Активированные аутореактивные Т-клетки могут способствовать формированию зародышевого центра и привлекать все большее количество аутореактивных B-клеток. IFN- $\gamma$ - интерферон-гамма; IL — интерлейкин; TGF- $\beta$ - трансформирующий фактор роста-бета; Th - T-хелпер; Treg - Т-регуляторные клетки.

диагностике локального заболевания, а с другой - к его систематизации и распространению на многие органы и ткани. Вот несколько фактов, подтверждающих данную гипотезу (рис. 2) [10].

\section{КЛИНИЧЕСКАЯ КАРТИНА}

Около 1/3 пациентов имеют в анамнезе заболевание атопической природы (бронхиальная астма, аллергический ринит, полипы полости носа, атопический дерматит). В отсутствие атопии в анамнезе у некоторых пациентов могут отмечаться эозинофилия и/или увеличение сывороточного уровня IgE [5, 7, 8]. Клинические симптомы lgG4-A3 представлены достаточно широко, чаще манифестируют в одном или нескольких органах, одновременно или последовательно. Заболевания могут носить подострый или хронический характер, проявлять себя спектром мягких локальных симптомов или массивным поражением тканей и органной недостаточностью. Среди наиболее характерных симптомов манифестации дисфункция почек, общая слабость, увеличение поднижнечелюстных или околоушных слюнных желез, снижение слуха, жажда. Данная характеристика IgG4-A3 наводит на мысль о том, что симптомы и особенности анамнеза носят весьма и весьма вариабельный характер, а это, в свою очередь, предъявляет требования к определенному уровню специфичности диагностических методов.

В 2019 г. исследователями США выделены основные четыре фенотипические группы IgG4-A3 [11]. Данные группы предполагают наличие систематизированной структуры, которая может использоваться для уточнения этиологии заболевания, выявления факторов риска и разработки персонализированных стратегий лечения. Наличие фенотипических групп lgG4-A3 способствует ранней диагностике, своевременному назначению патогенетической терапии и, как следствие, минимизации необратимого повреждения органов [11]. Учитывая полиорганную природу lgG4-A3, потенциальное число фенотипических групп составляет порядка нескольких тысяч, но большинство из них не применимы для клинической практики или научных исследований. Приведенные ниже четыре группы отличаются друг от друга распределением пораженных органов, демографических признаков пациента (раса, пол, возраст) и концентрации сывороточного lgG4.

- Группа 1: поражение преимущественно панкреатогепатобилиарной системы. Вероятность поражения поджелудочной железы в данной группе, по данным исследования, составила 87\%, желчного пузыря $55 \%$, печени - $13 \%$. 
- Группа 2: ретроперитонеальный фиброз (53\%) и/или аортит (22\%).

- Группа 3: ограниченное поражение структур головы и шеи по типу неполного синдрома Микулича. Вероятность поражения слезных желез в данной группе составила 60\%; подчелюстных желез - 50\%, околоушных желез - 22\%; орбит - 22\%.

- Группа 4: заболевания головы и шеи по схеме, соответствующей синдрому Микулича, а также системному полиорганному поражению. Вероятность поражения околоушной железы в группе 4 составила 49\%; поджелудочной железы - 46\%; легких - 39\%; почек $36 \%$; вероятность поражения орбит <1\%.

Что касается половозрастных характеристик данных групп, доля пациентов женского пола была значительно выше в группе 3 (76\%) по сравнению с группами 1, 2 и 4, где данный показатель был гораздо ниже и составил 21\%, $26 \%$ и 22\% соответственно [11]. Средний возраст при постановке диагноза был меньше в группе 3 (55 лет) по сравнению с другими тремя группами (58 лет - в группе 2 и 63 года - в группах 1 и 4) [11]. Расовое распределение также различалось по группам. Доля азиатских пациентов в группах 3 (67\%) и 4 (52\%) была значительно выше, чем в группах 1 (37\%) и 2 (25\%) [11]. Пациенты в группе 4 имели самые высокие концентрации IgG4 в сыворотке крови (медиана составила 1170 (интерквартильный размах (IQR) 520-2178) мг/дл), за которыми следовала группа 3 (445 (183-888) мг/дл) и группа 1 (316 (147-622) мг/дл); в группе 2 наблюдались самые низкие концентрации lgG4 в сыворотке крови (178 (63-322) мг/дл) [11].

\section{ДИАГНОСТИКА}

В 2011 г. Umehara и соавт. предложили критерии диагностики lgG4-АЗ для практического использования [12] (рис. 3). Однако в силу неспецифичности симптомов и изменений оцениваемых параметров диагностика IgG4-A3 должна базироваться на комплексном анализе клинических симптомов, лабораторных признаков, результатов гистологического исследования и данных визуализирующих методов.

При лабораторном обследовании пациентов c IgG4-А3 обычно выявляется повышение уровня lgG4, но концентрация его не может быть использована в качестве единственного диагностического критерия в силу низкой специфичности. В настоящее время обсуждается
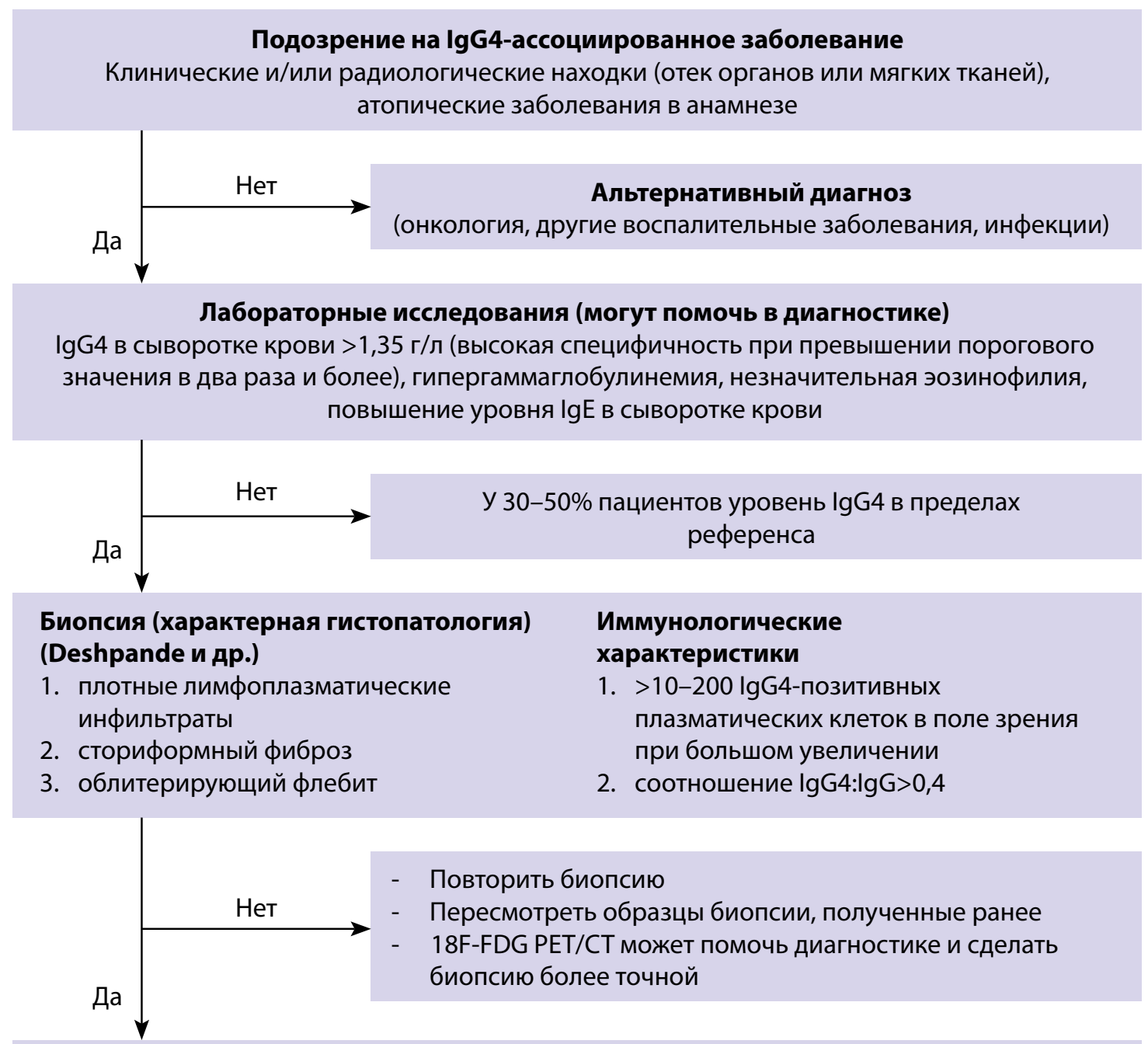

Повторить биопсию

Пересмотреть образцы биопсии, полученные ранее

18F-FDG PET/CT может помочь диагностике и сделать биопсию более точной

Совместимые клинические находки и типичная гистопатологическая картина

Диагноз: IgG4-ассоциированное заболевание 
возможность определения плазмобластов в качестве маркера заболевания, а золотым стандартом в диагностике lgG4-АЗ является биопсия с последующим описанием гистопатологической картины [13].

В 2019 г. при совместных усилиях специалистов Американской коллегии ревматологов (ACR) и Европейской лиги против ревматизма (EULAR) были разработаны и протестированы классификационные критерии lgG4-A3 с максимально возможной специфичностью при сохранении умеренно высокой чувствительности [14]. Классификационные критерии ACR и EULAR базируются на оценке серологических исследований крови, клинической картины, гистологического исследования пораженных органов и особенностей топического диагноза по данным полученных результатов лучевой диагностики [14]. Ценность разработанного набора критериев заключается в возможности постановки диагноза lgG4-A3 на основании проведенного исследования даже без выполнения биопсии пораженных органов при достижении достаточного количества баллов [14]. Предварительная оценка в 20 баллов и более определена как точка отсчета, при которой клинический случай соответствует критериям постановки IgG4-A3 (специфичность 97,8\%, чувствительность 82,0\%) [14].

Лабораторные исследования и клеточные маркеры в диагностике IgG4-A3

В связи с гетерогенностью исследований, направленных на изучение lgG4-A3, определение перечня необходимых параметров и их пороговых значений в диагностике этой патологии затруднено. Основные биомаркеры, характерные для lgG4-A3, представлены на рис. 4. Наиболее интересными представляются серологические параметры, а также маркеры фиброза. По различным данным, пороговое значение $\operatorname{lgG} 4$ в пределах 1,35-1,44 г/л в сыворотке крови обладает чувствительностью 87,2-97,0\% и специфичностью 79,6-82,6\% в диагностике IgG4-A3 [15, 16]. В одном из исследований было показано, что повышение порогового значения IgG4 до 2,8 г/л увеличивает специфичность исследования до 96,2\% и снижает чувствительность до 56,9\% [17]. Также информативно соотношение lgG4-положительных плазматических клеток и lgG-положительных плазматических клеток. Диагностический потенциал имеют сывороточные и тканевые уровни lgG4 и IgG2 [18]. Растворимый рецептор IL-2, определяемый в сыворотке (sIL-2R), в перспективе может стать маркером, отражающим активность заболевания и ответ на лечение, однако имеющиеся данные ограничены малой выборкой. Поэтому требуются дальнейшие проспективные исследования для подтверждения чувствительности и специфичности sIL-2R в диагностике lgG4-A3 [18].

Поскольку основным компонентом lgG4-АЗ является фиброзное воспаление, то логично предположить, что маркеры фиброза могут оказать помощь в диагностике данной патологии. По некоторым данным, сывороточный уровень лиганда CC-хемокина 18 (CCL18) был значительно выше у пациентов c lgG4-A3, чем в контрольной группе, а также прямо коррелировал с количеством пораженных органов, активностью заболевания, уровнем sIL2R [19], инфильтрацией тканей M2-макрофагами и степенью фиброза [20]. Кроме того, есть данные о повышении сывороточного уровня ламинина 511-E8 у пациентов c lgG4-A3 по сравнению с контрольной группой [21], а галектин-3, прохибитин и аннексин А11 могут принимать участие в патофизиологических процессах при lgG4-A3 [19].

Клеточным маркером воспалительного фиброза могут являться M2-макрофаги, следовательно, и связанные с ними цитокины (IL-33, IL-10, CCL18) [19]. В силу выраженных фиброзно-воспалительных изменений повышение уровня циркулирующих плазмобластов может рассматриваться в качестве одного из маркеров данной группы заболеваний (чувствительность 95\%, специфичность 82\%) $[22,23]$ и предиктора прогноза успешности терапии [24]. CD4+ цитотоксические Т-лимфоциты коррелируют с активностью заболевания и с количеством очагов поражения [24].

\section{Биопсия}

В настоящее время золотым стандартом диагностики lgG4-А3 являются данные биопсии [5]. Диагностика IgG4-A3 базируется на гистопатологической картине в вовлеченных органах, которая должна соответствовать следующим критериям:

1. наличие плотных лимфоплазматических инфильтратов;

2. сториформный фиброз;

3. облитерирующий флебит;

4. эозинофильная инфильтрация [5, 25].

Важным этапом изучения биоптата является проведение иммуногистохимического исследования, в ходе которого определяется соотношение lgG4+/lgG+ и количество клеток IgG4+/белков, способствующих гибернации (hpf) [14].

$\begin{gathered}\text { Общеклинический } \\ \text { анализ крови }\end{gathered}$
$\uparrow$ СРБ
$\uparrow$ СОЭ
тромбоцитоз
эозинофилия
$\downarrow$ гемоглобина
$\downarrow$ эритроцитов

$\begin{gathered}\text { Серологические } \\ \text { исследования }\end{gathered}$
$\uparrow \lg$
$\lg \mathrm{g} 4>1,35$ г/л
$\lg \mathrm{G} 2>5,3$ г/л
антинуклеарные
антитела
ревматоидный
фактор
гипокомплементемия
( $\downarrow$ С3)

\section{Молекулярная} визуализация

ПЭТ/KT с 18F-FDG, 68Ga-FAPI 
Молекулярная визуализация в диагностике Ig G4-A3

Весьма интересны перспективы диагностики lgG4-A3 с позиции молекулярной визуализации. На первых порах она заключалась в применении 18F-ФДГ ПЭТ/КТ (фтордезоксиглюкозы, меченной радиоактивным изотопом фтора-18, позитронно-эмиссионной (ПЭТ) и компьютерной томографии (КТ)), что давало свои плоды: это позволяло определять локализацию участков воспаления, оценивать распространение заболевания, принимать решение относительно биопсии и использовалось при мониторинге ответа на терапию.

Однако в последнее время появились сообщения о более информативном визуализирующем исследовании в рамках IgG4-A3, а именно 68Ga-FAPI ПЭТ/КT (ингибитор белка-активатора фибробластов, меченный радиоизотопом галлий-68 ПЭТ/КТ) [26, 27].

В августе 2019 г. опубликован опыт визуализации lgG4-АЗ при помощи 18F-ФДГ ПЭТ/КТ и 68Ga-FAPI ПЭТ/КТ. У пациента с титром lgG4 в сыворотке крови 11300 мг/л (при референсном интервале 80-1400 мг/л) по данным 18F-ФДГ ПЭТ/КТ выявлены участки накопления ФДГ в лимфоузлах шеи и средостения и в правом легком; также участки с повышенным накоплением ФДГ выявлялись в околоушной железе и подчелюстной железе. По данным 68Ga-FAPI ПЭТ/КТ выявлено интенсивное накопление радиофармпрепарата в тех же участках, что и по данным 18F-ФДГ ПЭТ/КТ, но дополнительно обнаружены участки накопления в поджелудочной железе [28]. Это делает 68Ga-FAPI более специфичным в отношении визуализации очагов lgG4-A3, что, вероятно, обусловлено выраженностью фиброзного компонента [28].

\section{IGG4-АЗ В ПРАКТИКЕ ЭНДОКРИНОЛОГА}

IgG4-ассоциированные дакриоаденит и сиалоаденит

В настоящее время болезнь Микулича (БМ) и хронический склерозирующий сиалоаденит (опухоль Кюттнера) определены как часть спектра IgG4-АЗ. Для болезни Микулича характерно двустороннее симметричное поражение слезных и всех групп слюнных желез вследствие массивной лимфоплазмоцитарной инфильтрации без нарушения их функции. Болеют в основном женщины среднего возраста. В отличие от других заболеваний, входящих B lgG4-А3, при БМ никогда не формируется фиброз [29].

Опухоль Кюттнера является IgG4-ассоциированным сиалоаденитом и поражает одну или обе поднижнечелюстные железы [30]. Характеризуется прогрессирующим перидуктальным фиброзом, формированием лимфоидных фолликулов, расширением протоков с массивной лимфоплазмоцитарной инфильтрацией, атрофией ацинусов [29].

Патология щитовидной железы (тиреоидит Риделя, фиброзирующий аутоиммунный тиреоидит)

Тиреоидит Риделя (ТР) - крайне редкое, медленно прогрессирующее воспалительное заболевание щитовидной железы, при котором одна или обе доли увеличиваются и замещаются соединительной тканью, что сопровождается компрессией соседних структур шеи; фиброзирование часто распространяется за пределы капсулы щитовидной железы и поражает соседние органы [7]. Обычно зоб твердый, так называемой «каменистой плотности», и спаянный с окружающими тканями. Пациентов беспокоят одышка, осиплость голоса, затруднение дыхания и глотания [8].

Для большинства пациентов с ТР характерен эутиреоз. Нарушение функции щитовидной железы происходит из-за обширного замещения железистой ткани нефункционирующей соединительной тканью [7]. В таком случае чаще всего выявляется гипотиреоз с повышенными титрами антител к тиреоглобулину (АТ ТГ) и тиреопероксидазе (АТ ТПО). По данным обзора 185 пациентов с ТР из Cleveland Clinic выявлено, что у 64\% наблюдался эутиреоз, у 32\% - гипотиреоз и у 4\% - тиреотоксикоз [7].

Кроме TP, в спектре IgG4-A3 рассматриваются и другие патологии щитовидной железы, а именно фиброзирующий аутоиммунный тиреоидит (тиреоидит Хашимото, АИТ) и болезнь Грейвса. Чаще встречается у молодых мужчин со значительно повышенным уровнем АТ ТГ и АТ ТПО. По данным ультразвукового исследования характерна пониженная эхогенность ткани щитовидной железы [6]. У пациентов с IgG4-опосредованным АИТ наблюдают более высокий риск развития гипотиреоза и значительное увеличение щитовидной железы, что часто служит показанием к тиреоидэктомии [5].

IgG4-ассоциированная офтальмопатия (IgG4-AO)

lgG4-AO имеет тенденцию к появлению безболезненного экзофтальма и диплопии. Характеризуется рецидивирующим течением, и чаще всего демонстрируется сочетанное c lgG4-AO двустороннее увеличение слезных желез. Kaк lgG4-AO, так и не связанные c lgG4 идиопатические орбитальные воспалительные заболевания обычно отвечают на терапию глюкокортикоидами. Тем не менее частота рецидивов после прекращения приема глюкокортикоидов, как правило, выше у IgG4-AO (67\% против 30\%), и рецидив возникает раньше (средний срок развития рецидива - 1 месяц против 5 месяцев) [31].

\section{ТЕРАПИЯ IGG4-АЗ СЕГОДНЯ И В ПЕРСПЕКТИВЕ}

По данным международного консенсуса по лечению lgG-A3 2015 г., 87\% экспертов придерживаются мнения о том, что медикаментозная терапия показана всем пациентам с симптомами активной фазы заболевания, тогда как пациенты с бессимптомным течением не всегда требуют немедленного начала терапии [32]. Тем не менее своевременное начало лечения ведет к более быстрой и полной ремиссии. В качестве препаратов первой линии для индукции ремиссии предлагаются глюкокортикостероиды (ГКС) либо их комбинация базовыми противовоспалительными препаратами (БПВП) [30, 32, 33].

В метаанализе 2019 г. рассматривали различные варианты индукции ремиссии у пациентов с IgG4-A3 [34]. Так, комбинация ГКС и БПВП ассоциирована с более высокой вероятностью ремиссии по сравнению с монотерапией ГКС, БПВП и ритуксимабом [34]. В качестве поддерживающей же терапии наибольшей эффективностью обладает ритуксимаб, а наиболее безопасна в плане развития побочных эффектов монотерапия БПВП [34].

Часто в комбинации с ГКС назначают тамоксифен селективный антагонист эстрогена, который может быть использован в качестве монотерапии (у пациентов с резистентностью к ГКС) или как адъювантная терапия с целью уменьшения дозы ГКС. Данный препарат снижает 
экспрессию TGF- $\beta$, что может приводить к замедлению фиброзирования ткани. Описано несколько случаев уменьшения очага соединительной ткани и редукции симптомов основного заболевания на фоне терапии тамоксифеном [7]. В клинических обзорах обсуждаются дозы тамоксифена в диапазоне от 10 до 20 мг/сут [8]. При резистентности к терапии ГКС/комбинации ГКС с тамоксифеном или монотерапии тамоксифеном рекомендуется лечение ритуксимабом [7]. Ритуксимаб представляет собой генно-инженерные химерные моноклональные антитела мыши или человека, обладающие специфичностью к CD20-антигену (CD20-АГ), локализованному на поверхности пре-В-лимфоцитов и зрелых В-лимфоцитов. По структуре ритуксимаб относится к IgG1. Fab-фрагмент ритуксимаба связывается с CD20-АГ на лимфоцитах и при участии Fс-домена инициирует иммунологические реакции, опосредующие лизис В-клеток [6]. Снижение уровня IgG4 на фоне несущественных изменений других подклассов IgG при терапии ритуксимабом может объясняться тем, что клетки IgG4+ более короткоживущие, чем клетки, экспрессирующие другие подклассы lgG [35]. Антифиброзирующий эффект ритуксимаба может быть обусловлен снижением активности миофибробластов у пациентов с IgG4-A3 [35]. Ритуксимаб представляется многообещающим препаратом для лечения lgG4-A3, особенно случаев, резистентных к другой терапии, и с эпизодами рецидива в анамнезе. При этом базальные уровни lgG4 и lgЕ в сыворотке крови являются достоверными предикторами рецидива [34].

Оценка продукции интерферона 1 типа (I-IFN) и интерлейкина-33 (I-IFN/IL-33) может быть интересна в качестве терапевтической мишени у пациентов c lgG4-A3, поскольку при данных заболеваниях повышается продукция плазмацитоидными дендритными клетками I-IFN и, как следствие, увеличивается уровень IL-33, играющего важную роль в воспалительных заболеваниях и фиброзе [36].

При отрицательном ответе на консервативную терапию и, как результат, увеличении щитовидной железы со значительной компрессией трахеи и пищевода проводится оперативное лечение (тиреоидэктомия). При этом частота хирургических осложнений (парез возвратного гортанного нерва, гипопаратиреоз и др.) приближается к 39\% случаев, даже в экспертных руках, вследствие плотной спаянности щитовидной железы с окружающими тканями. В таких ситуациях для устранения симптомов компрессии ограничиваются гемитиреоидэктомией или удалением перешейка [5].

\section{ЗАКЛЮЧЕНИЕ}

Выяснение общих звеньев этиопатогенеза различных заболеваний позволяет существенно улучшить их диагностику и лечение, в перспективе - профилактику. В качестве примера можно рассматривать lgG4-ассоциированные эндокринные заболевания. С использованием специализированных мультимодальных (лабораторных и инструментальных) методов обследования можно быстро и точно установить диагноз, распространенность, клинический прогноз, выбрать оптимальный метод лечения и оценить ответ на него. Необходимыми условиями для этого являются постоянное обновление доказательных знаний и междисциплинарная коммуникация. Необходимы дальнейшие углубленные мультидисциплинарные исследования с целью совершенствования диагностических и лечебных алгоритмов IgG4-A3 с привлечением иммунологов, эндокринологов, патологов, радиологов и других специалистов.

\section{ДОПОЛНИТЕЛЬНАЯ ИНФОРМАЦИЯ}

Источник финансирования. Поисково-аналитическая работа и подготовка статьи проведена на личные средства авторского коллектива.

Конфликт интересов. Авторы декларируют отсутствие явных и потенциальных конфликтов интересов, связанных с публикацией настоящей статьи.

Участие авторов. Все авторы внесли значимый вклад в подготовку статьи, прочли и одобрили финальную версию.

\section{СПИСОК ЛИТЕРАТУРЫ | REFERENCES}

1. Офицеров В.И. Подклассы иммуноглобулина G: возможности использования в диагностической практике: метод. пособие. Кольцово: Вектор-Бест, 2005. - 19 с. [Ofitserov VI. Podklassy imunoglobulina G: vozmozhnosti ispol'zovaniya $v$ diagnosticheskoy praktike: metod. posobie. Kol'tsovo: Vektor-Best; 2005. 19 p. (In Russ).]

2. Aalberse RC, Stapel SO, Schuurman J, Rispens T. Immunoglobulin G4: an odd antibody. Clin Exp Allergy. 2009;39(4):469-477. doi: 469-7710.1111/j.1365-2222.2009.03207.x

3. Deshmukh TM, Shah RR, Gurav YK, Arankalle VA. Serum immunoglobulin $G$ subclass responses in different phases of hepatitis $E$ virus infection. J Med Virol. 2013;85(5):828-832. doi: 10.1002/jmv.23537.

4. Collins AM, Jackson KJ. A temporal model of human IgE and IgG antibody function. Front Immunol. 2013;4:235. doi: 10.3389/fimmu.2013.00235.

5. Rotondi M, Carbone A, Coperchini F, et al. Diagnosis of endocrine disease lgG4-related thyroid autoimmune disease. Eur J Endocrinol. 2019;180(5):R175-R183. doi: 10.1530/EJE-18-1024.

6. Юкина М.Ю., Трошина Е.А., Платонова Н.М., Нуралиева Н.Ф. Аутоиммунная lgG4-ассоциированная эндокринная патология // Ожирение и метаболизм. — 2017. — Т.14. — №3. — С. 43-47. [Yukina MYu, Troshina EA, Platonova NM, Nuralieva NF. The autoimmune lgG4 - associated endocrine pathology. Obesity and metabolism. 2017;14(3):43-47. (In Russ).] doi: 10.14341/omet2017343-47.

7. Karim AF, Verdijk RM, Guenoun J, et al. An inflammatory condition with different faces: immunoglobulin G4-related disease. Neth J Med. 2016;74(3):110-115.
8. Vasaitis L. IgG4-related disease: A relatively new concept for clinicians. Eur J Intern Med. 2016;27:1-9. doi: 10.1016/j.ejim.2015.09.022.

9. Ishikawa Y, Terao C. Genetic analysis of IgG4-related disease. Mod Rheumatol. 2019;30(1):17-23. doi: 10.1080/14397595.2019.1621000.

10. Morales A, Cignarella A, Jabeen IS, et al. An update on IgG4-related lung disease. Eur J Intern Med. 2019;66:18-24. doi: 10.1016/j.ejim.2019.06.010.

11. Wallace ZS, Zhang Y, Perugino CA, et al. Clinical phenotypes of IgG4-related disease: an analysis of two international cross-sectional cohorts. Ann Rheum Dis. 2019;78(3):406-412. doi: 10.1136/annrheumdis-2018-214603.

12. Umehara H, Okazaki K, Masaki Y, et al. Comprehensive diagnostic criteria for lgG4- related disease (IgG4-RD), 2011. Mod Rheumatol. 2012;22(1):21-30. doi: 10.1007/s10165-011-0571-z.

13. Chen $\mathrm{H}$, Lin W, Wang $\mathrm{Q}$, et al. IgG4-related disease in a Chinese cohort: a prospective study. Scand J Rheumatol. 2014;43(1):70-74. doi: 10.3109/03009742.2013.822094.

14. Wallace ZS, Naden RP, Chari S, et al. The 2019 American College of Rheumatology/European League Against Rheumatism classification criteria for lgG -related disease. Ann Rheum Dis. 2020;79(1):77-87. doi: 10.1136/ annrheumdis-2019-216561.

15. Masaki Y, Kurose N, Yamamoto M, et al. Cutoff values of serum lgG4 and histopathological lgG4+ plasma cells for diagnosis of patients with lgG4-related disease. Int J Rheumatol. 2012:580814. doi: $10.1155 / 2012 / 580814$ 
16. Hao M, Liu M, Fan G, et al. Diagnostic value of serum lgG4 for IgG4-related disease: a PRISMA-compliant systematic review and Meta-analysis. Medicine (Baltimore). 2016;95(21):e3785. doi: 10.1097/MD.0000000000003785

17. Culver EL, Sadler R, Simpson D, et al. Elevated serum lgG4 levels in diagnosis, treatment response, organ involvement, and relapse in a prospective lgG4-related disease UK cohort. Am J Gastroenterol. 2016;111(5):733-743. doi: 10.1038/ajg.2016.40

18. Tang J, Cai S, Ye C, et al. Biomarkers in lgG4-related disease: a systematic review. Semin Arthritis Rheum. 2020;50(2):354-359. doi: 10.1016/j.semarthrit.2019.06.018.

19. Akiyama M, Yasuoka H, Yoshimoto K, et al. CC-chemokine ligand 18 is a useful biomarker associated with disease activity in IgG4-related disease. Ann Rheum Dis. 2018;77(9):1386-1387. doi: 10.1136/annrheumdis-2017-212110.

20. Furukawa S, MoriyamaM, Tanaka A, et al. Preferential M2 macrophages contribute to fibrosis in IgG4-related dacryoadenitis and sialoadenitis, so-called Mikulicz's disease. Clin Immunol. 2015;156(1):9-18. doi: 10.1016/j.clim.2014.10.008.

21. Shiokawa M, Kodama Y, Sekiguchi K, et al. Laminin 511 is a target antigen in autoimmune pancreatitis. Sci Trans/ Med. 2018:10(453):eaaq0997. doi: 10.1126/scitranslmed.aaq0997.

22. Della-Torre E, Rigamonti E, Perugino C, et al. B lymphocytes directly contribute to tissue fibrosis in patients with lgG4-related disease J Allergy Clin Immunol. doi: 10.1016/j.jaci.2019.07.004.

23. Wallace ZS, Mattoo H, Carruthers M, et al. Plasmablasts as a biomarker for lgG4-Related disease, independent of serum IgG4 concentrations. Ann Rheum Dis. 2015;74(1):190-195. doi: 10.1136/annrheumdis-2014-205233.

24. Lanzillotta M, Della-Torre E, Milani R, et al. Effects of glucocorticoids on B-cell subpopulations in patients with lgG4-related disease. Clin Exp Rheumatol. 2019;37Suppl 118(3):159-166.

25. Kamisawa T, Zen Y, Pillai S, et al. lgG4-related disease. Lancet. 2015;385(9976):1460-1471. doi: 10.1016/50140-6736(14)60720-0.

26. Giesel FL, Heussel CP, Lindner T, et al. FAPI-PET/CT improves staging in a lung cancer patient with cerebral metastasis. Eur J Nucl Med Mol Imaging. 2019;46(8):1754-1755. doi: 10.1007/s00259-019-04346-z.
27. Kratochwil C, Flechsig P, Lindner T, et al. 68Ga-FAPI PET/CT: tracer uptake in 28 Different kinds of cancer. J Nucl Med. 2019;60(6):801-805. doi: 10.2967/jnumed.119.227967.

28. Luo Y, Pan Q, Zhang W. IgG4-related disease revealed by 68Ga-FAPI and 18F-FDG PET/CT. Eur J Nucl Med Mol Imaging. 2019;46(12):2625-2626. doi: 10.1007/s00259-019-04478-2.

29. Седышев С.Х., Васильев В.И., Ковригина А.М., Насонов ЕЛ. lgg4связанное системное заболевание. Современный взгляд на «Старые» болезни // Научно-практическая ревматология. 2012. — №5. - C. 64-72. [Sedyshev SKh, Vasiliev VI, Kovriguina AM, Nasonov EL. lgg4-linked systemic disease. Modern outlook on «Old» disease. Nauchno-prakticheskaia revmatologiia. 2012;(5):64-72. (In Russ).]

30. Kurowecki D, Patlas MN, Haider EA, et al. Cross-sectional pictorial review of IgG4-related disease. Br J Radiol. 2019;92(1103):20190448. doi: 10.1259/bjr.20190448.

31. Dean T. Jeffery, Hillary R. Kelly, 40 - lgG4-Related Disease in the Head and Neck, Neuroradiology, 2019, Pages 308-317, ISBN 9780323445498 https://doi.org/10.1016/B978-0-323-44549-8.00040-7.

32. Khosroshahi A, Wallace ZS, Crowe JL, et al. International consensus guidance statement on the management and treatment of IgG4-Related disease. Arthritis Rheumatol. 2015;67(7):1688-1699. doi: 10.1002/art.39132

33. Ahn C, Kang S, Sa HS. Clinicopathologic features of biopsied lacrimal gland masses in 95 Korean patients. Graefes Arch Clin Exp Ophthalmol. 2019;257(7):1527-1533. doi: 10.1007/s00417-019-04327-w.

34. Omar D, Chen Y, Cong Y, et al. Glucocorticoids and steroid sparing medications monotherapies or in combination for IgG4-RD: a systematic review and network meta-analysis. Rheumatology (Oxford). 2020;59(4):718-726. doi: 10.1093/rheumatology/kez380.

35. Сокол Е.В., Васильев В.И. Лечение lgG4-связанного заболевания // Научно-практическая ревматология. — 2016. — Т.54. — №3. C. 352-360. [Sokol EV, Vasilyev VI. Treatment of IgG4-related disease. Nauchno-prakticheskaia revmatologiia. 2016;54(3):352-360. (In Russ).] doi: 10.14412/1995-4484-2016-352-360

36. Watanabe T, Minaga K, Kamata K, et al. Mechanistic insights into autoimmune pancreatitis and IgG4-Related disease. Trends Immunol. 2018;39(11):874-889. doi: 10.1016/j.it.2018.09.005.

Рукопись получена: 26.01.2020. Одобрена к публикации: 30.04.2020. Опубликована online: 28.07.2020.

\section{ИНФОРМАЦИЯ ОБ АВТОРАХ [AUTHORS INFO]}

*Румянцев Павел Олегович, д.м.н. [Pavel O. Rumyantsev, MD, PhD]; адрес: 117036, ул. Дмитрия Ульянова, д. 11, к. 2 [address: Dmitry Ulyanova street 11k2, 117036 Moscow, Russia]; e-mail: pavelrum@gmail.com; ORCID: 0000-0002-7721-634X; eLibrary SPIN: 7085-7976.

Козлов Иван Генрихович, д.м.н., профессор [lvan G. Kozlov, MD, PhD]; e-mail: immunopharmacology@yandex.ru; ORCID: 0000-0002-9694-5687; eLibrary SPIN: 5877-2101.

Колпакова Евгения Александровна, ординатор [Evgenia A. Kolpakova, resident]; e-mail: colpakova.ev@mail.ru; ORCID: 0000-0003-2283-8958; eLibrary SPIN: 5040-8628.

Чухачева Ольга Сергеевна, врач-эндокринолог [Olga S. Chukhacheva, endocrinologist]; e-mail: ochukhacheva@gmail. com; ORCID: 0000-0001-5675-5419; eLibrary SPIN: 3484-6222.

Коренев Сергей Владимирович, д.М.Н., профессор [Sergey S. Korenev, MD, PhD]; e-mail: korenevsv@mail.ru; ORCID: 0000-0003-2310-0576; eLibrary SPIN: 5257-4476

Гончаров Андрей Геннадьевич, К.M.H. [Andrei G. Goncharov, MD, PhD]; e-mail: agoncharov59@mail.ru ; ORCID: 0000-0001-6967-8838; eLibrary SPIN: 6638-9367.

Уланова Елена Юрьевна, старший преподаватель [Elena U. Goncharov]; e-mail: ulanova.eu@gmail.com; ORCID: 0000-0002-9331-7933. eLibrary SPIN: 7355-8137

\section{ЦИТИРОВАТЬ:}

Румянцев П.О., Чухачева О.С., Козлов И.Г., Колпакова Е.А., Коренев С.В., Гончаров А.Г., Уланова Е.Ю. IgG4-ассоциированные заболевания в эндокринологии // Проблемы эндокринологии. - 2020. - Т. 66. - №2. - С. 24-32. doi: https://doi.org/10.14341/probl12285

\section{TO CITE THIS ARTICLE:}

Rumyantsev PO, Kozlov IG, Kolpakova EA, Chukhacheva OS, Korenev SV, Goncharov AG, Goncharov EU. IgG4-related diseases in endocrinology. Problems of Endocrinology. 2020;66(2):24-32. doi: https://doi.org/10.14341/probl12285 